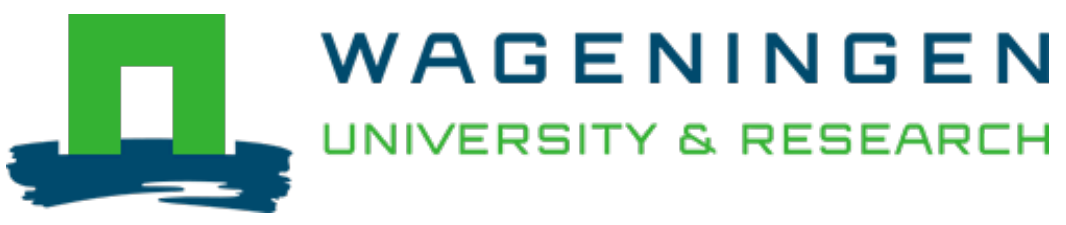

\title{
Ergosterol content of Rhizopus oligosporus NRRL 5905 grown in liquid and solid substrates.
}

\author{
Applied Microbiology and Biotechnology \\ Nout, M.J.R.; Bonants-van Laarhoven, T.M.G.; Jongh, P.; Koster, P.G. \\ https://doi.org/10.1007/bf00253532
}

\begin{abstract}
This publication is made publicly available in the institutional repository of Wageningen University and Research, under the terms of article $25 \mathrm{fa}$ of the Dutch Copyright Act, also known as the Amendment Taverne. This has been done with explicit consent by the author.
\end{abstract}

Article 25 fa states that the author of a short scientific work funded either wholly or partially by Dutch public funds is entitled to make that work publicly available for no consideration following a reasonable period of time after the work was first published, provided that clear reference is made to the source of the first publication of the work.

This publication is distributed under The Association of Universities in the Netherlands (VSNU) 'Article $25 \mathrm{fa}$ implementation' project. In this project research outputs of researchers employed by Dutch Universities that comply with the legal requirements of Article $25 \mathrm{fa}$ of the Dutch Copyright Act are distributed online and free of cost or other barriers in institutional repositories. Research outputs are distributed six months after their first online publication in the original published version and with proper attribution to the source of the original publication.

You are permitted to download and use the publication for personal purposes. All rights remain with the author(s) and / or copyright owner(s) of this work. Any use of the publication or parts of it other than authorised under article $25 \mathrm{fa}$ of the Dutch Copyright act is prohibited. Wageningen University \& Research and the author(s) of this publication shall not be held responsible or liable for any damages resulting from your (re)use of this publication.

For questions regarding the public availability of this publication please contact openscience.library@wur.nl 
Appl Microbiol Biotechnol (1987) 26:456-461

\title{
Ergosterol content of Rhizopus oligosporus NRRL 5905 grown in liquid and solid substrates
}

\author{
M. J. R. Nout ${ }^{1}$, T. M. G. Bonants-van Laarhoven' ${ }^{1}$, P. de Jongh ${ }^{1}$, and P. G. de Koster ${ }^{2}$ \\ 1 Department of Food Science, Agricultural University, and \\ 2 DMV Campina, Veghel, The Netherlands
}

Summary. The ergosterol content of Rhizopus oligosporus NRRL 5905 varied between $2-24 \mu \mathrm{g} /$ $\mathrm{mg}$ biomass dry matter when grown in laboratory media and was found to be influenced by the substrate composition.

When grown on a natural substrate (soya beans) the ergosterol content was considerably higher (estimated at approx. $60-90 \mu \mathrm{g} / \mathrm{mg}$ biomass dry matter).

In laboratory media, the ergosterol content was also influenced by the extent of aeration and the growth phase of the mycelium; within the range of $25^{\circ} \mathrm{C}-35^{\circ} \mathrm{C}$, the incubation temperature did not influence the ergosterol content significantly.

In view of these variations, ergosterol should not be used as a chemical index for the quantification of biomass grown in static solid-substrate fermentations with limited mass transfer, e.g. tempe or oncom.

\section{Introduction}

The industrial importance of solid-substrate fermentations (SSF) as applied in the oriental-food industry, manufacture of mould-ripened cheeses, composting and spawn production was mentioned by Cannel and Moo-Young (1980a, b) and Matcham et al. (1985).

The optimisation and process control of fermentation conditions require reliable and preferably rapid methods for the determination of microbial biomass.

Offprint requests to: M. J. R. Nout, Department of Food Science, Agricultural University, De Dreijen 12, 6703 BC Wageningen, The Netherlands
Due to mycelium penetration and attachment to the substrate, techniques for bacterial or yeast biomass determination (Harris and Kell 1985) are not always suitable in the case of fungal SSF.

Enumeration of fungal propagules is subject to high coefficients of variation and reflects a degree of sporulation rather than biomass (Jarvis et al. 1983; Nout 1984).

Specific attempts to monitor fungal biomass in SSF's have been made with e.g. the asbestos-koji method (Sakaguchi et al. 1955), nylon-paste method (Yamamoto 1957), enzymatic degradation of the substrate and subsequent collection of biomass by filtration (Charles and Gavin 1977), measuring the texture of the fermented substrate (Kronenberg and Hang 1985), measuring $\mathrm{CO}_{2}$ and heat production (Rathbun and Shuler 1983; Finger et al. 1976), determination of the chitin content of the fermented substrate (Arima and Uozumi 1967; Cousin et al. 1984; Matcham et al. 1985 ) and by determination of the laccase activity during the fermentation (Matcham et al. 1985).

The latter also compared the chitin and laccase methods with the determination of ergosterol, the predominant sterol in fungi. They observed a good correlation between the biomass of Agaricus bisporus grown on liquid medium and the total ergosterol yield, and found the ergosterol content a more sensitive chemical index for low levels of mycelial growth than chitin or laccase activity.

Based on an ergosterol content of $2.2 \mu \mathrm{g} / \mathrm{mg}$ dry weight mycelium grown on liquid substrate, they predicted from the ergosterol content of colonised rye grain that it would contain $10 \mathrm{mg}$ dry weight mycelium per $\mathrm{g}$ dry weight grain.

Since the determination of ergosterol by GLC or direct UV-spectroscopy as carried out by Matcham et al. (1985) was not entirely satisfactory, 
they recommended the use of the HPLC-method as employed by Seitz et al. (1977). Our interest in the tempe fermentation prompted us to investigate the possible use of ergosterol as a chemical index for the quantification of Rhizopus oligosporus biomass growing on liquid and solid substrates. Our particular interest was the predictability of the ergosterol content of the fungal fermented material under varying conditions of age and culturing conditions.

\section{Materials and methods}

\section{Organism}

Rhizopus oligosporus NRRL 5905, classified by Schipper and Stalpers (1984) as Rhizopus microsporus var. oligosporus, was grown at $30^{\circ} \mathrm{C}$ and maintained on malt extract agar (Oxoid, CM 59).

\section{Spore suspension}

$R$. oligosporus was grown on mung bean sprout agar for 1 week at $30^{\circ} \mathrm{C}$ to achieve dense sporulation. Mung bean sprout agar contained $60 \mathrm{~g}$ sucrose, $20 \mathrm{~g}$ agar and $1000 \mathrm{~g}$ mung bean sprout extract, obtained by boiling $100 \mathrm{~g}$ mung bean sprouts (Vigna radiata) in 11 dist. water for $30 \mathrm{~min}$, followed by filtration and adjusting to $1000 \mathrm{~g}$ with dist. water. The sporangia were scraped from the agar and suspended in sterile dist. water $+1 \%$ Tween 80 , collected by centrifugation at $3000 \mathrm{rpm}$ for $15 \mathrm{~min}$, washed and suspended in sterile dist. water to obtain a suspension containing $5 \cdot 10^{5}-3 \cdot 10^{6}$ viable spores $/ \mathrm{ml}$. This suspension could be stored at $4^{\circ} \mathrm{C}$ for 7 days without significant loss of viability.

\section{Liquid cultures}

Conical flasks ( $250 \mathrm{ml}$ size) containing $100 \mathrm{ml}$ sterile Tryptone Soya broth (TSB, Oxoid CM 129), TSB + $2 \%$ glucose (TSBG), or malt extract broth (MEB, Oxoid CM 57) were inoculated with approx. $10^{5}$ viable spores $/ \mathrm{ml}$ and incubated either stationary or in a temperature controlled rotary shaker $(120 \mathrm{rpm})$. Experiments at reduced oxygen concentration were carried out in an incubator permanently flushed with a mixture of $97 \%$ $\mathrm{N}_{2}$ and $3 \% \mathrm{O}_{2}$.

\section{Solid cultures}

Experiments on agar medium were carried out with TSB solidified with $1.2 \%$ agar in $14.5 \mathrm{~cm}$ diam. petri dishes, inoculated by placing a drop of spore suspension containing approx. $10^{4}$ viable spores at the centre of the plates.

Growth on soya beans was studied after they had been prepared for tempe manufacture, as follows: $1 \mathrm{~kg}$ of dry dehulled yellow var. soya beans were rinsed twice with tapwater, mixed with 31 tapwater of $45^{\circ} \mathrm{C}$, and soaked at $25^{\circ} \mathrm{C}$ for $18-$ $24 \mathrm{~h}$. After discarding the soakwater, the beans were rinsed once with tapwater, boiled in clean tapwater for $20-25 \mathrm{~min}$, collected on a colander and allowed to cool and dry superficially, while spread in a layer of $1-2 \mathrm{~cm}$ thickness. After cool- ing to room temperature, the beans were inoculated with approx. $10^{5}$ spores/g as mentioned by Ko and Hesseltine (1979), placed in a single layer in perforated petri dishes and incubated at $30^{\circ} \mathrm{C}$.

\section{Dry matter}

Fungal dry matter in liquid medium was collected in a buchner funnel on a pre-weighed filterpaper (Schleicher and Schüll 520b), rinsed with dist. water, dried at $80^{\circ} \mathrm{C}$ for $24 \mathrm{~h}$, cooled in a desiccator, and weighed.

Fungal dry matter on solid agar medium was removed, together with the agar medium, from the petri dish, placed in a glass beaker with $250 \mathrm{ml}$ tapwater $+0.05 \%$ Tween 20 , and heated in a microwave oven, causing the agar medium to melt and diffuse into the water. The fungal mass remained intact and was collected, rinsed, dried and weighed.

Fungal biomass grown on soya beans was estimated as follows: duplicate samples of soya bean cultures were homogenised with dist. water for $2 \mathrm{~min}$ (Colworth Stomacher, type 400 ) to give $1: 5$ dilutions. These were diluted with an equal volume of a $0.12 \%$ methylene blue solution to improve the contrast for microscopic viewing. A known weight of the resulting $1: 10$ dilution (approx. $0.06 \mathrm{~g}$ ) was placed on duplicate microscope slideglasses, and covered with $18 \times 18 \mathrm{~mm}$ cover slips. Alternatively, methylene blue was omitted and $1: 10$ dilutions in water were used for photographic purposes. Of each wet mount, 10 microscopic fields (magn. $135 \times$ ) were randomly selected and photographed (Zeiss, Axiomat). The volume of the visible fungal mass was calculated from its estimated length and diameter, and compared with a series of similarly prepared mounts of increasing known weights of fungal mass pre-grown in liquid substrate and suspended in sterile soya beans, using a Waring blender.

\section{Ergosterol}

An amount of $0.1 \mathrm{~g}$ of comminuted and lyophilised mycelium sample or $0.5-1 \mathrm{~g}$ of a similarly prepared sample of soya bean culture was homogenised for $2 \mathrm{~min}$ with $25 \mathrm{ml}$ abs. ethanol pro analysis using an Ultra Turrax blender.

The slurry was transferred into a $250 \mathrm{ml}$ round-bottom flask and $25 \mathrm{ml} 2 \mathrm{~N}$ ethanolic $\mathrm{NaOH}$ and 3 boiling chips were added. Saponification was carried out by refluxing for $1 \mathrm{~h}$. After cooling, solids were removed by centrifugation for $20 \mathrm{~min}$ at $2500 \mathrm{rpm}$. The supernatant was transferred into a separatory funnel together with $50 \mathrm{ml}$ dist. water. The pellet was resuspended in $10 \mathrm{ml}$ petroleum ether (PE) b.p. $60^{\circ}$. $80^{\circ} \mathrm{C}$ (techn. grade), centrifuged for $20 \mathrm{~min}$ at $2500 \mathrm{rpm}$, and the supernatant added to the saponified mixture in the separatory funnel. After shaking, the PE fraction was collected, and the watery phase was extracted with $3 \times 50 \mathrm{ml}$ PE b.p. $60^{\circ}-$ $80^{\circ} \mathrm{C}$. The four combined PE fractions were evaporated to dryness in a vacuum rotary film evaporator (water bath temperature $40^{\circ} \mathrm{C}$ ). Traces of water were removed by dissolving the residue in $10 \mathrm{ml}$ acetone followed by evaporation to dryness as above. The residue was finally dissolved in $5 \mathrm{ml}$ abs. ethanol.

After filtration through a 0.45 micron Millipore filter, aliquots of $20 \mu \mathrm{l}$ were injected onto a 10 ODS Sphercolumn, $250 \times 4.6 \mathrm{~mm}$ (Chrompack), protected by a Nucleosil ( $30-35$ micron) pre-column (Waters), fitted in a SpectraPhysics SP 8000 HPLC with a variable wavelength detector at $282 \mathrm{~nm}$ (Kratos Spectraflow 773; bandwith $5 \mathrm{~nm}$ ). Chromatographic conditions: mobile phase methanol: water ( $92 / 8$ v.v.), flow 1.5 
$\mathrm{ml} / \mathrm{min}$, column temperature $40^{\circ} \mathrm{C}$, retention time ergosterol approx. $12 \mathrm{~min}$. A standard solution of ergosterol (Sigma $\mathrm{E}$ 6625 ) in abs. ethanol was used for quantification purposes.

\section{Results and discussion}

\section{Determination of ergosterol and its distribution}

The frequently cited procedure of Seitz et al. (1977) involving chromatography of a saponified extract of the sample does not allow non-extractable ergosterol derivatives to be measured. Such membrane-bound ergosterol derivatives could be extracted however, after preliminary saponification of the sample. With the described method a recovery of $95 \%$ of ergosterol standard solutions was obtained.

Since a 20 hour exposure to diffuse daylight caused a loss of $1.6 \%$ of the ergosterol in a $50 \mathrm{mg} /$ 1 solution, samples intended for storage longer than 1 hour were kept in the dark.

We obtained a coefficient of variation (c.v. $=\sigma / \mu \cdot 100 \%$ ) of the ergosterol determination method of $3.0 \%$ (5 replicate analyses of 1 sample of $R$. oligosporus mycelium grown in TSB), an accuracy similar to that achieved by Delaveau et al. (1983). We obtained a c.v. of $15.7 \%$ for the ergosterol content of the fungal biomass, comparing favourably with that of the biomass itself, viz.: c.v. $30.4 \%$ (both calculated from single analyses of five replicate cultures).

Table 1 shows that in a liquid TSB culture, only $4 \%$ of all detected ergosterol was found to be excreted into the medium. For this reason and also to avoid having to lyophilise large volumes of liquid medium, we limited ourselves whenever possible to the ergosterol content of the fungal mass only. From the same table it shows that approx. $10 \%$ of the biomass ergosterol is derivatised,

Table 1. Distribution of ergosterol in Rhizopus oligosporus (24hour TSB shaking culture at $30^{\circ} \mathrm{C}$ )

Medium:

4.0

Biomass:

Ethanol extractable without prior saponification:

Ergosterol

Ergosteryl esters (determined as ergosterol after their saponification)

Ethanol extractable only after saponification of biomass:

Ergosteryl esters (determined as ergosterol)

Total ergosterol the majority of which is probably cellwall- or membrane-coupled and only to be extracted and detected after having been released by saponification of the biomass. A smaller quantity of ergosterol derivatives is ethanol soluble without prior saponification of the biomass, as well as the freely occurring ergosterol which constitutes the majority of total detectable ergosterol. Since we could not assume the ratio given in Table 1 to be constant, most samples of biomass were analysed for total ergosterol.

\section{Ergosterol content of $R$. oligosporus biomass grown on defined growth media}

Using defined growth media and conditions permitting the gravimetric determination of biomass dry weight, the influence of incubation time, composition of the substrate, culturing conditions, aeration and temperature were investigated as summarised in Fig. 1 A-D.

Seitz et al. (1979) compared chitin and ergosterol contents of fungal biomass grown on liquid malt extract media. Alternaria alternata contained $3.8-4.4 \mu \mathrm{g}$ ergosterol $/ \mathrm{mg}$ dry weight (5 and 10 days incubation, respectively), Aspergillus flavus $2.3-3.3 \mu \mathrm{g} / \mathrm{mg}$ (2.1 and 7 days, resp.) and $A$. amstelodami $5.9-4.9 \mu \mathrm{g} / \mathrm{mg}$ (3.6 and 8.6 days, resp.). Seitz and Pomeranz (1983) reported the ergosterol content of sclerotia of Claviceps purpurea of unstated age, removed from ergoty cereals and grasses, to vary between $0.2-0.83 \mu \mathrm{g} / \mathrm{mg}$ dry weight. Matcham et al. (1985) found ergosterol contents of $2-2.7 \mu \mathrm{g} / \mathrm{mg}$ dry weight in Agaricus bisporus between 21 and 56 days of incubation on a liquid medium. At 56 days the stationary phase had just been reached; no data were given beyond that stage.

Except for those given by Seitz and Pomeranz (1983) for C. purpurea, the above ergosterol contents are comparable to the ones found by us in $R$. oligosporus when grown in or on liquid media during the stage of rapid growth.

However, our results indicate that the ergosterol content of $R$. oligosporus biomass may become significantly higher as influenced by the composition of the substrate, the extent of aeration and the age of the fungal material. The tested incubation temperatures had no significant effect.

Weete et al. (1973) already mentioned the need for more data concerning the changes in total lipids and sterol contents during the fungal life cycle. The gradual increase of the ergosterol content found by us is most likely caused by the de- 

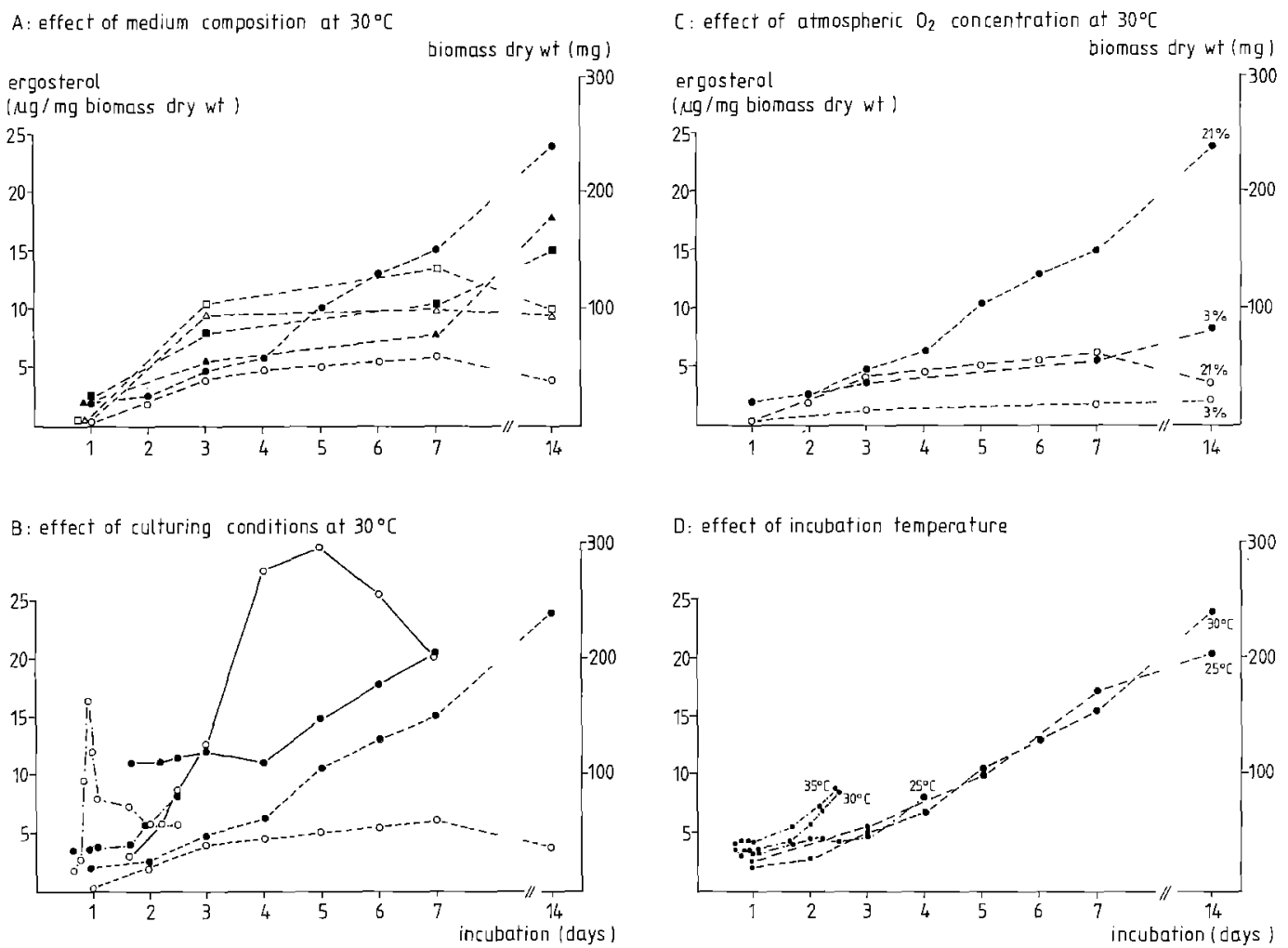

Fig. 1. Influence of environmental conditions on the yield of Rhizopus oligosporus biomass and its ergosterol content. TSB (tryptone soya broth or agar): ergosterol $\bullet$; biomass $\mathrm{O}$. TSB $+2 \%$ glucose: ergosterol $\Delta$; biomass $\triangle$. MEB (malt extract broth): ergosterol $\square$; biomass $\square$. —— Solid medium; --.-- liquid medium (stationary culture); -...-.- liquid medium (shaking culture)

crease of the biomass dry weight due to senescence and death. The phenomenon of a sudden, almost linear increase of the ergosterol content beyond the stationary growth phase became particularly evident during the experiments on solid agar medium (Fig. 1B); a similar, albeit more gradual pattern emerges from the experiments in liquid cultures.

The influence of aeration was significant. Whereas well-aerated biomass of $R$. oligosporus grown on a solid agar surface had an initial ergosterol content of $11 \mu \mathrm{g} / \mathrm{mg}$ dry weight (Fig. 1B), the biomass grown in liquid medium at $3 \% \mathrm{O}_{2}$ contained only $2.1 \mu \mathrm{g} / \mathrm{mg}$ which remained significantly lower than that of liquid grown biomass at $21 \% \mathrm{O}_{2}$ (Fig. 1C). This effect appears similar to that observed in Saccharomyces uvarum by Delaveau et al. (1983) who reported that this yeast was unable to produce ergosterol under anaerobic conditions, and that the ergosterol in aerobicallygrown yeast disappeared gradually during anaerobic growth.

The influence of oxygen availability on the ergosterol content may have important practical consequences if ergosterol were to be used as a chemical index for the quantification of biomass produced in static solid-substrate fermentations such as the tempe fermentation.

During tempe manufacture, a stationary packed bed of cooked soya beans is overgrown and penetrated by fungi, mainly $R$. oligosporus. Practical experience has shown (Ko and Hesseltine 1979) that the soya bean bed should not exceed approx. $5 \mathrm{~cm}$ thickness since otherwise mould growth would be impaired by lack of oxygen. Rathbun and Shuler (1983) found that $R$. oligosporus still showed relatively rapid growth at $1-6.5 \% \mathrm{O}_{2}$ but that no growth occurred at $0.23-0.32 \% \mathrm{O}_{2}$.

Assuming a bed of $5 \mathrm{~cm}$ thickness with air access from both sides, and a concentration of $1 \%$ $\mathrm{O}_{2}$ in the centre (still permitting fungal growth), the $\mathrm{O}_{2}$ gradient in fermenting tempe could be estimated at $(21-1 \%) / 2.5 \mathrm{~cm}=8 \% \mathrm{O}_{2} / \mathrm{cm}$ depth, approximately. Considering the effect of $\mathrm{O}_{2}$ concentration on the ergosterol content of the biomass, it should therefore be expected that the ergosterol content of the biomass will decrease towards the 
Table 2. Aerobic growth and biomass ergosterol content of Rhizopus oligosporus on soya beans at $30^{\circ} \mathrm{C}$

\begin{tabular}{lllll}
$\begin{array}{l}\text { Incubation } \\
\text { period } \\
(\mathrm{h})\end{array}$ & $\begin{array}{l}\text { Estimated biomass } \\
\text { fresh weight } \\
(\%, \mathrm{w} / \mathrm{w})\end{array}$ & $\begin{array}{l}\text { dry matter } \\
(\mathrm{mg} / \mathrm{g} \text { tempe dry wt) }\end{array}$ & $\begin{array}{l}\text { Ergosterol } \\
(\mu \mathrm{g} / \mathrm{g} \text { tempe } \\
\text { dry wt) }\end{array}$ & $\begin{array}{l}\text { Estimated biomass } \\
\text { ergosterol content } \\
(\mu \mathrm{mg} \text { biomass dry wt) }\end{array}$ \\
\hline 24 & 1.0 & 4.5 & 420 & 93 \\
48 & 5.8 & 27.2 & 1940 & 71 \\
72 & 9.5 & 50.4 & 3230 & 64 \\
\hline
\end{tabular}

centre of the bed during this and similar static SSF's, and consequently, that it will not be of much value as a chemical index for biomass.

The biomass ergosterol content may be more homogenous during agitated SSF's in rotating drum fermenters (Lindenfelser and Ciegler 1975) with controlled atmospheric conditions.

\section{Ergosterol content of $R$. oligosporus biomass grown on soya beans}

Table 2 presents data of $R$. oligosporus grown on soya beans. In order to minimise the effect of aeration, the beans were incubated as single layers in petri dishes under aerobic conditions.

The photomicroscopic method which we employed to estimate the quantity of biomass proved to be cumbersome. In addition, the accuracy of this method leaves much to be desired since its low recovery $(20 \%-25 \%)$ requires considerable extrapolation of measured data. Nevertheless, the obtained estimates are comparable to those of Charles and Gavin (1977) who obtained 10\% biomass during the rapid growth phase of $R$. oligosporus in tempe.

Since the soya beans themselves did not contain detectable amounts of ergosterol, and the predominant soya sterols $\beta$-sitosterol and stigmasterol do not absorb light of $282 \mathrm{~nm}$, there is no doubt that the gradual increase of the ergosterol content of the fermenting beans is due to the fungal growth.

The estimated biomass ergosterol content in soya beans was of the order of $60-90 \mu \mathrm{g} / \mathrm{mg}$ biomass dry matter and underlines the strong effect of substrate composition as was illustrated in Fig. $1 \mathrm{~A}$.

During the experiments summarized in Table 2 , the combined presence of (a) soya compounds (e.g. fatty acids) which can be incorporated into the ergosterol synthesis pathway, and (b) an unlimited supply of oxygen, resulted in biomass ergosterol contents which are approximately 10 -fold higher than those reported in the literature (and confirmed by us) in defined liquid growth media.

Our data therefore rule out the possibility of predicting the biomass grown in natural substrates on the basis of the ergosterol content of biomass grown on defined laboratory media.

\section{References}

Arima K, Uozumi T (1967) A new method for the estimation of the mycelial weight in koji. Agric Biol Chem 31:119-123

Cannel E, Moo-Young M (1980a) Solid-state fermentation systems. Process Biochem 15:2, 4, 6-7

Cannel E, Moo-Young M (1980b) Solid-state fermentation systems. Process Biochem 15:24-28

Charles M, Gavin JR (1977) Engineering studies of the tempe fermentation. In: Steinkraus KH (ed) Handbook of indigenous fermented foods. Marcel Dekker, New York, pp 74--87

Cousin MA, Zeidler CS, Nelson PE (1984) Chemical detection of mold in processed foods. J Food Sci 49:439-445

Delaveau J, Lipus G, Moll M (1983) Importance des stérols au cours du cycle de la levure de brasserie. Bios 14:37-40

Finger SM, Hatch RT, Regan TM (1976) Aerobic microbial growth in semisolid matrices: heat and mass transfer limitation. Biotechnol Bioeng 18:1193-1218

Harris CM, Kell DB (1985) The estimation of microbial biomass. Biosensors 1:17-84

Jarvis B, Seiler DAL, Ould AJL, Williams AP (1983) Observations on the enumeration of moulds in food and feedingstuffs. J Appl Bact 55:325-336

Ko SD, Hesseltine CW (1979) Tempe and related foods. In: Rose AH (ed) Economic Microbiology, Vol. 4. Microbial Biomass. Academic Press, London, pp 115-140

Kronenberg H-J, Hang YD (1985) A puncture test method for monitoring solid substrate fermentation. J Food Sci 50:539-540

Lindenfelser LA, Ciegler A (1975) Solid-substrate fermentor for ochratoxin A production. Appl Microbiol 29:323-327

Matcham SE, Jordan BR, Wood DA (1985) Estimation of fungal biomass in a solid substrate by three independent methods. Appl Microbiol Biotechnol 21:108-112

Nout MJR (1984) Influence of sample size and analytical procedure on the variance of surface mould plate counts of maizekernels. Chem MikrobiolTechnol Lebensm 8:133 - 136

Rathbun BL, Shuler ML (1983) Heat and mass transfer effects in static solid-substrate fermentations: design of fermentation chambers. Biotechnol Bioeng 25:929-938

Sakaguchi K, Okazaki H, Takeuchi M (1955) A note on the comparison of koji and submerged cultures. J Agr Chem Soc Japan 29:349 
Schipper MAA, Stalpers JA (1984) A revision of the genus Rhizopus. 2. The Rhizopus microsporus group. Studies in Mycology (Baarn) No. 25:20-34

Seitz LM, Mohr HE, Burroughs R, Sauer DB (1977) Ergosterol as an indicator of fungal invasion in grains. Cereal Chem $54: 1207-1217$

Seitz LM, Sauer DB, Burroughs R, Mohr HE, Hubbard JD (1979) Ergosterol as a measure of fungal growth. Phytopath $69: 1202-1203$

Seitz LM, Pomeranz Y (1983) Ergosterol, ergosta-4,6,8(14),22- tetraen-3-one, ergosterol peroxide, and chitin in ergoty barley, rye and other grasses. J Agric Food Chem 31:1036-1038

Weete JD, Lawler GC, Laseter JL (1973) Total lipid and sterol components of Rhizopus arrhizus: identification and metabolism. Arch Biochem Biophys 155:411-419

Yamamoto K (1957) Studies on koji. 1. A new analytical method of koji. Bull Agr Chem Soc Japan 21:308-312

Received February 23, 1987/Revised April 15, 1987 